Revue d'histoire de l'Amérique française

REVUE D.HISTOIRE DE L'AMÉRIQUE FRANÇAISE

\title{
Le premier imprimé d'Amérique en 1532
}

\section{Gustave Lanctot}

Volume 8, numéro 3, décembre 1954

URI : https://id.erudit.org/iderudit/301671ar

DOI : https://doi.org/10.7202/301671ar

Aller au sommaire du numéro

Éditeur(s)

Institut d'histoire de l'Amérique française

ISSN

0035-2357 (imprimé)

1492-1383 (numérique)

Découvrir la revue

Citer ce compte rendu

Lanctot, G. (1954). Compte rendu de [Le premier imprimé d’Amérique en 1532].

Revue d'histoire de l'Amérique française, 8(3), 443-443.

https://doi.org/10.7202/301671ar d'utilisation que vous pouvez consulter en ligne.

https://apropos.erudit.org/fr/usagers/politique-dutilisation/ 


\section{LE PREMIER IMPRIME D'AMERIQUE EN 1532}

Dans le numéro de la Revue d'bistoire de l'Amérique française, juin 1954, Mademoiselle Marie-Claire Daveluy passe en revue, avec une sympathie évidente, les contributions du groupe des Dix à leur dix-huitième Cabier. Bibliothécaire de longue expérience et bibliographe de forte technique, c'est aux Propos de bibliopbile de M. Victor Morin qu'elle réserve sa critique, d'ailleurs, très avertie. Elle n'accepte pas son affirmation que l'introduction de l'imprimerie en Amérique revient à Juan Pablos, imprimeur à Mexico en 1536. Elle cite un érudit espagnol, José Toribio Médina, pour attribuer cette distinction à Estebeau Martin, imprimeur, qui aurait mis le pied à Mexico entre 1535 et 1539 , tandis que Pablos ne serait arrivé qu'en cette dernière année 1539. Dautre part, la distinguée bibliographe se range à l'opinion de MM. Aegidius Fauteux et Victor Morin que le premier ouvrage sorti d'une presse en Amérique serait l'Escala Spiritual, quoique Medina déclare qu'il parut sans porter de date ni de nom d'éditeur et qu'une récente opinion l'attribue à l'année 1539 . On reste un peu perplexe devant toutes ces affirmations, parce qu'on ne sait positivement ni quand ni par qui fut imprimé le premier livre. De même reste-t-il douteux qu'Estabau Martin ait pu établir sa boutique avant d'obtenir ses lettres de naturalisation, qui sont de septembre 1539 .

La controverse reste vaine et même périmée depuis un an. Car la plus haute compétence du jour en la matière, Francisco Vinde, assure que l'imprimerie fit ses débuts en Amérique, à Mexico, en 1531, avec l'arrivée, cette année-là d'une petite presse, qui servait à imprimer des cartes à jouer. L'imprimeur se nommait Pedro Varela, qui était le fils de l'imprimeur Juan Varela, de Salamanque, qui entretenait des relations d'affaires avec le Mexique. De cette presse rudimentaire sortit, entre 1532 et 1534 , et plus probablement en 1532, le premier imprimé d'Amérique sous le titre : Rezo del Santo Rosario, c'est-à-dire Dévotion du Saint-Rosaire. Ainsi ce serait à Varela que s'appliquerait la lettre, du 6 mai 1538, de Monseigneur Zumarraga, faisant allusion à la présence d'un imprimeur à Mexico, et non à Juan Pablos, encore en Espagne à cette date, non plus qu'à Estabau Martin, qui ne devait recevoir ses lettres de naturalisation qu'un an plus tard. L'Escala Spiritual de MM. Fauteux et Morin doit donc céder la première place au Rezo del Santo Rosario. Ce qui réjouira tous les militants de l'année mariale de savoir que le premier livre d'Amérique fut imprimé en l'honneur de la Vierge Marie.

\section{Gustave LANCTOT}

MARION, Séraphin, de la Société royale, Littérateurs et moralistes du Canada français d'autrefois. Les éditions de "l'Eclair", Hull, Canada. Editions de l'Université, Ottawa, Canada. 191 pages, avec Avant-propos.

M. Marion nous offre, en ce dernier ouvrage, le VIIIe tome d'une 